\title{
Endocardial fibroelastosis and hypoplasia of the left ventricle in neonates without significant aortic stenosis
}

\author{
PHILIP C URSELL, ^ CATHERINE A NEILL, ROBERT H ANDERSON, SIEW Y HO, \\ ANTON E BECKER, LEON M GERLIS
}

From the Department of Paediatrics, Cardiothoracic Institute, Brompton Hospital, London; the Department of Pathology, Academisch Medisch Centrum, University of Amsterdam and Interuniversity Institute, the Netherlands; and the Cardiac Research Unit, Killingbeck Hospital, Leeds

SUMMARY Endocardial fibroelastosis in neonates with hypoplasia of the left ventricle is usually associated with severe aortic stenosis or atresia. In this study three hearts were examined, in which severe hypoplasia of the left ventricular cavity with myocardial hypertrophy and endocardial fibroelastosis were associated with small but non-stenotic subaortic outflow tracts and aortic valves. These features were contrasted with those of neonatal left heart hypoplasia in aortic stenosis and atresia. The index cases were examples of the very rare contracted form of endocardial fibroelastosis.

Endocardial fibroelastosis-thickening of the endocardial layer by abundant collagen and elastic tissue-is uncommon and usually identified in association with malformations of the left ventricle. When cardiac malformations are present the endocardial fibroelastosis is often considered to be secondary to the malformation, although this is by no means proved. Endocardial fibroelastosis lining a hypoplastic ventricular cavity is, however, usually associated with aortic atresia or severe aortic stenosis. The primary form of endocardial fibroelastosis is that which occurs as a seemingly isolated phenomenon in anatomically normal hearts. Although its aetiology and pathogenesis are obscure, primary endocardial fibroelastosis has been related to various factors. ${ }^{12}$ Infective ${ }^{34}$ and metabolic ${ }^{56}$ agents have been implicated as well as the effects of hypoxia ${ }^{7}$ or lymphatic obstruction. ${ }^{8}$ Other workers have focused on a nonspecific response to raised intramyocardial tension. ${ }^{9}$ Familial incidence is reported in humans and animals, ${ }^{1011}$ but genetic mechanisms remain unclear. Irrespective of its cause this form of endocardial fibroelastosis, usually associated with a dilated left ventricle, can in most cases be classified as a congestive (dilated) cardiomyopathy of childhood.

Requests for reprints to Professor R H Anderson, Department of Paediatrics, Cardiothoracic Institute, Brompton Hospital, Fulham Road, London SW3 6HP.

*Present address: Columbia University, New York, USA.

Accepted for publication 1 December 1983
Nevertheless, there is another very rare form of primary endocardial fibroelastosis, the so called restrictive or contracted form. ${ }^{12}$ In this type the endocardial fibroelastosis lines a small left ventricular cavity, but there is no associated mitral valve disease or significant outflow tract obstruction. Apart from its initial description, ${ }^{12}$ we are unaware of any subsequent detailed account of this entity, although Keith et al have reviewed it in general terms. ${ }^{13}$ To date we have seen three cases of this rare contracted form of primary endocardial fibroelastosis. In this study, we analysed the clinicopathological features with special reference to left ventricular morphology and aortic root size and compared them with those of cases of hypoplastic left heart syndrome associated with aortic atresia or aortic stenosis.

\section{Materials and methods}

The first case (case 1) of neonatal fibroelastosis without significant left ventricular outflow tract obstruction was seen recently at the Brompton Hospital, London. To ascertain if similar cases in infants less than 1 month old existed with this contracted form of endocardial fibroelastosis we reviewed the cardiac pathology records at the Brompton Hospital, the Hospital for Sick Children, London, the Academisch Medisch Centrum, Amsterdam, and the Cardiac Research Centre, Killingbeck Hospital, Leeds. Two similar cases (cases 2 and 3) were found in the Leeds records. We also discovered 46 cases of neonatal 
Table Summary of cases

\begin{tabular}{|c|c|c|c|c|c|c|c|}
\hline \multirow[t]{2}{*}{ Case No } & \multirow{2}{*}{$\begin{array}{l}\text { Age at } \\
\text { death } \\
\text { (days) }\end{array}$} & \multirow[t]{2}{*}{ Clinical findings } & \multicolumn{5}{|l|}{ Necropsy findings } \\
\hline & & & Mitral valoe & $L V$ wall & $\begin{array}{l}\text { Endocandial } \\
\text { thichness (mom) }\end{array}$ & $\begin{array}{l}\text { Sire of } \\
\text { corta }(\operatorname{mon})\end{array}$ & Aortic valoe \\
\hline 1 & 1 & \multirow{3}{*}{$\begin{array}{l}\text { Pale and cyanosed, } \\
\text { poor pulses } \\
\text { Pale and cyanosed, } \\
\text { poor pulses } \\
\text { Pale and cyanosed, } \\
\text { poor pulses }\end{array}$} & \multirow{3}{*}{$\begin{array}{l}\text { Small, short } \\
\text { chordae } \\
\text { Small, short } \\
\text { chordae } \\
\text { Almost normal }\end{array}$} & \multirow{3}{*}{$\begin{array}{l}\text { Hypertrophied } \\
(+++) \\
\text { Hypertrophied } \\
(+++) \\
\text { Hypertrophied } \\
(++)\end{array}$} & 3 & 3.5 & Bileaflet, non-stenotic \\
\hline 2 & 2 & & & & 1 & 6 & Trileaflet, minimal stenosis \\
\hline 3 & 3 & & & & 1.5 & 6 & Trileaflet, non-stenotic \\
\hline
\end{tabular}

++ , moderately; +++ , severely; LV, left ventricular.

fibroelastosis in the presence of significant congenital malformations of the left side of the heart. From these we selected two cases for comparison with the index case. All the hearts had been fixed in $10 \%$ buffered formaldehyde. After the heart in case 1 had been photographed and sectioned in four chamber long axis planes (right angles to the inlet part of the ventricular septum) a block of tissue incorporating the left atrium and left ventricle was removed and prepared for histological study using standard methods. In addition to haemotoxylin and eosin, sections were stained with Masson's trichrome and elastic van Gieson's stains.

\section{Results}

The clinical presentation, investigations, and necropsy findings are shown in the Table.

\section{ANATOMICAL FEATURES}

All three hearts were normally structured and connected, and the salient features were in the left ventricle and its outflow tract. They were remarkably similar in the three cases and can be illustrated by reference to those in case 1 . The mitral orifice was smaller than normal, but the mitral valve leaflets were unremarkable. The tendinous chords of the mitral valve, however, were short and thick (Fig. 1a). The hypertrophied slit-like left ventricle was completely lined by a dense white layer of fibrous tissue measuring up to $0.3 \mathrm{~cm}$ in thickness (Fig. 1b). A thick white cord of fibrous tissue traversed the ventricular cavity from the septum to the anterolateral free wall. The aortic valve was bicuspid but otherwise normal (Fig. 1c), and the aortic annulus measured $0.5 \mathrm{~cm}$ in diameter. The calibre of the ascending aorta appeared small but measured at least $0.35 \mathrm{~cm}$ in diameter at all points (Fig. 1b). Discrete coarctation of the aorta was not present. The duct was closed with a surgical clip.

\section{HISTOLOGICAL FEATURES}

Histologically, the thickened endocardium was composed of numerous spindle shaped fibroblast-like cells amidst abundant collagenous tissue and elastic fibres lying parallel with the ventricular cavity (Fig. 2). Several slit-like crevices (sinusoids) lined by endocardial fibroelastosis extended from the left ventricular cavity through the inner one third of the myocardial wall. In addition, there was perivascular fibrosis of the intramyocardial vessels. Two small infarcts composed of calcified dense fibrous tissue were identified in the myocardium. The thick cord identified on gross examination contained a central core of cardiac muscle cells around which there were concentric layers of fibroelastotic tissue. Except for contraction bands in subendocardial muscle cells, the remainder of the myocardium was histologically normal.

\section{Discussion}

In 1960 Edwards classified endocardial fibroelastosis as occurring in a "dilated" and a "contracted" form based upon the size of the left ventricle. ${ }^{12}$ Since this classification was introduced it has been used by pathologist and cardiologist alike. ${ }^{14} 15$ Of the many cases of the contracted form of endocardial fibroelastosis, the overwhelming majority are associated with significant left ventricular outflow tract obstruction. They comprise the so called hypoplastic left heart syndrome ${ }^{16}{ }^{17}$ and some cases of critical neonatal aortic stenosis. ${ }^{18} 19$ The contracted form of endocardial fibroelastosis without significant left ventricular outflow tract obstruction or other major cardiac malformations is rarely reported. ${ }^{13}$ In neonates it is a very rare condition.

Since the left ventricular outflow tract was not obstructed in any of our cases, they are examples of primary endocardial fibroelastosis or at least primary cardiomyopathy with reactive endocardial fibroelastosis. The concept of endocardial fibroelastosis representing reactive tissue which increases in thickness with time has been emphasised by others. ${ }^{41120}$ In our cases much of the thickness of the left ventricular wall was fibroelastotic tissue. Even without the endocardial fibroelastosis, however, the myocardial hypertrophy was severe (Fig. 1b). The relatively inelastic and poorly compliant fibroelastotic tissue undoubtedly further constrained the distensibility and compliance 


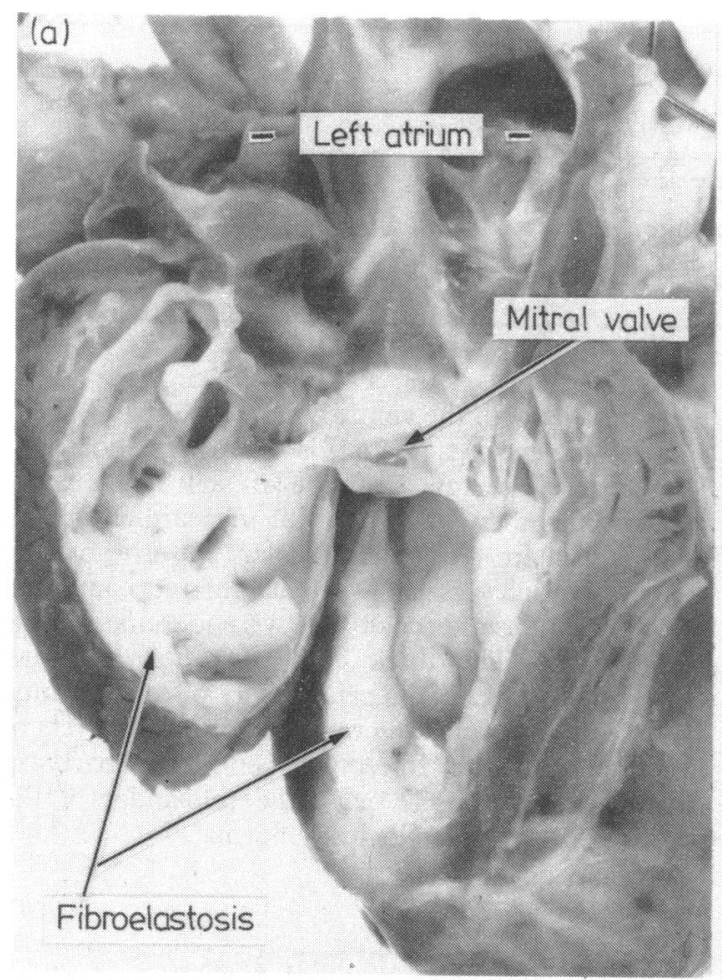

(b)

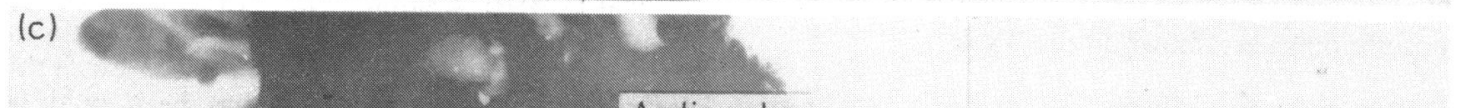

Right ventricle
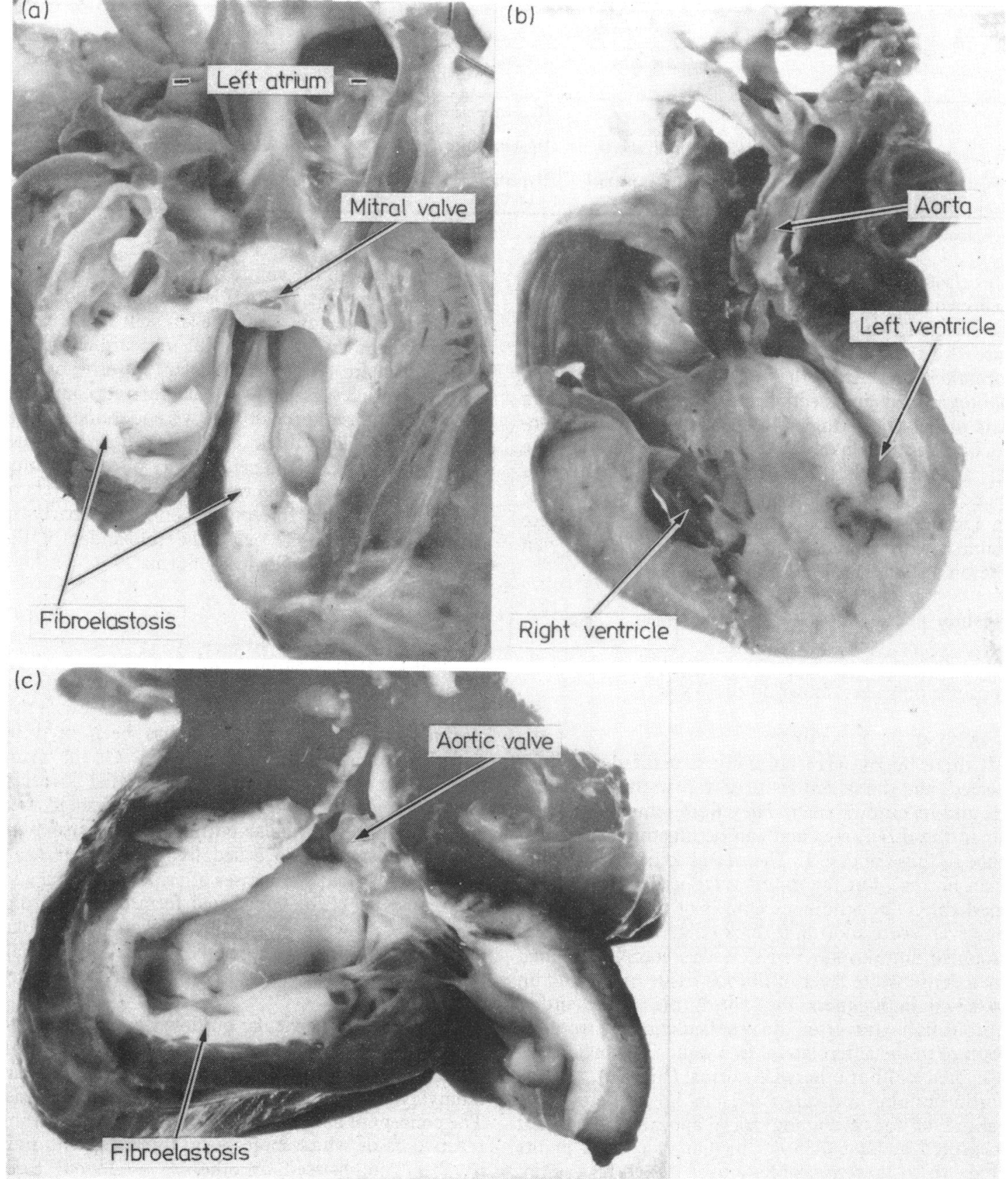

Fig. 1 Morphological appearance of (a) left atrium and left ventricle showing thick endocardial fibroelastosis and thickened tendinous chords of the mitral valve; (b) long axis section showing a tiny lefi ventricular cavity, thick endocardial fibroelastosis, und non-stenotic aortic annulus; and (c) lefi ventricular view showing non-obstructive aortic outlet. 


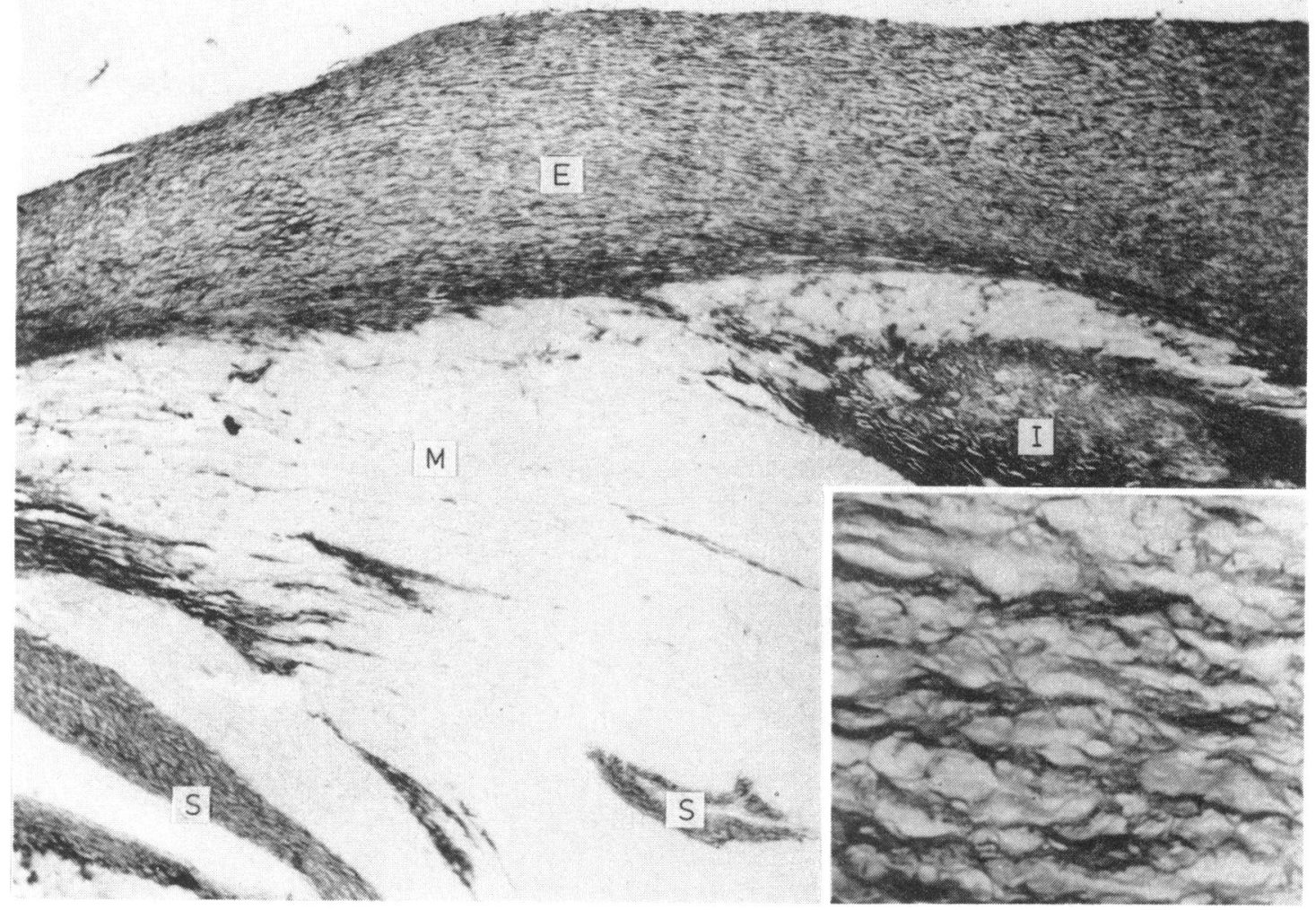

Fig. 2 Histological section of the left ventricle showing the abnormally thick endocardium $(E)$ overlying myocardium $(M)$. Slit-like crevices (sinusoids $(S)$ ) are lined by thickened endocardium. A healed myocardial infarct $(I)$ consisting of calcified densefibrous tissue is present within the subendocardial region. At higher magnification (inset) the endocardial tissue is seen to contain wavy dark staining elastic fibres lying parallel.

of the left ventricle before and after birth.

The small calibre of the ascending aorta was presumably a consequence of diminished blood flow through the ascending aorta secondary to left ventricular dysfunction in utero. Aortic size has been correlated with left ventricular volume in animal fetuses. ${ }^{21}$ In case 1 the diameter of the ascending aorta corresponded to that of a 26 week human fetus and in cases 2 and 3 to that of one of 28 weeks. ${ }^{22}$ This almost certainly indicates that the left ventricular disease antedated the twenty eighth week of gestation.

We compared the cases of endocardial fibroelastosis without significant outflow tract obstruction with a case of endocardial fibroelastosis associated with moderately severe aortic stenosis and a case of endocardial fibroelastosis associated with aortic atresia. The left ventricles of the two latter hearts were small teardrop shaped cavities with appreciably hypertrophied ventricular walls (Fig. 3). There was a gradation in the amount of fibroelastotic tissue from less than $0.5 \mathrm{~mm}$ thickness in the case of aortic atresia to $3 \mathrm{~mm}$ in the left ventricle of the Brompton case without significant outflow tract obstruction. The mitral valves of all the hearts were somewhat hypoplastic but otherwise normal. Patency of the mitral orifice appeared to be a prerequisite for the development of endocardial fibroelastosis in the left ventricle. ${ }^{13}$ Clearly, the left ventricular cavity is grossly distorted when the "contracted" form of endocardial fibroelastosis is present. We believe that this is the major adverse factor accounting for the usually poor outcome of these patients $^{23}$ : neonates with critical aortic stenosis, hypoplasia of the ascending aorta, and endocardial fibroelastosis with sinusoids have a poor prognosis with or without surgery. ${ }^{18} 19$

By limiting our study of endocardial fibroelastosis to necropsy findings in neonates of less than 1 month old we minimised complicating factors such as time and treatment. Primary endocardial fibroelastosis in older children may well be a process similar to that occurring in infants, but the onset of the disease is less well defined. In our cases the disorder was unequivoc- 


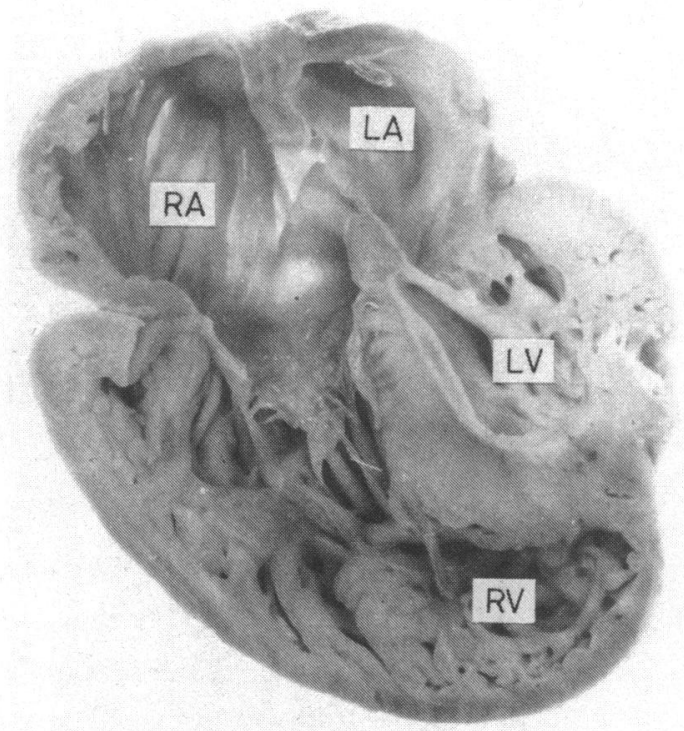

(a)

(b)

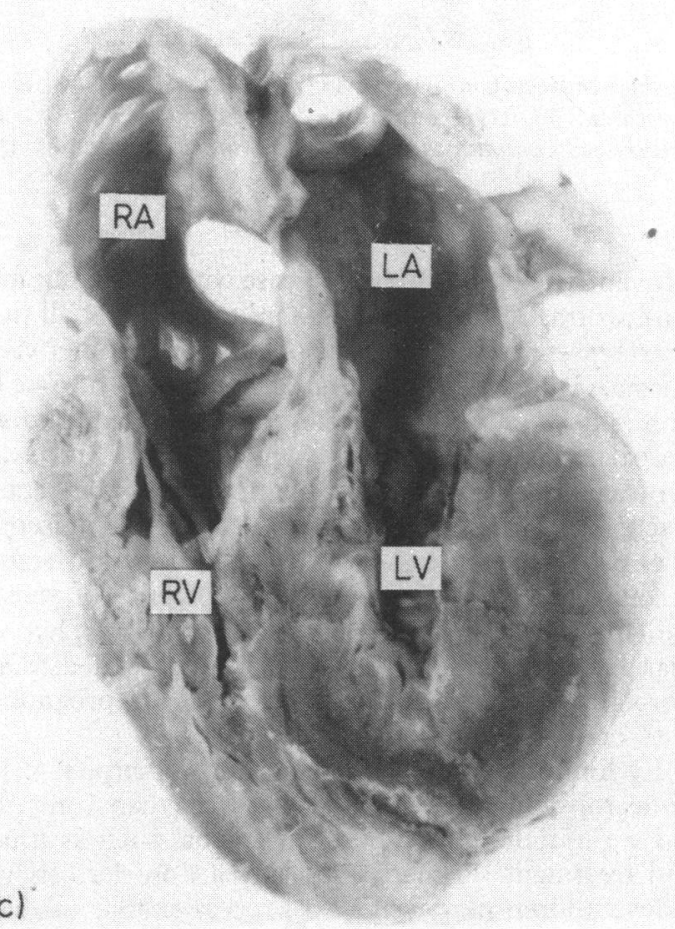

(d)

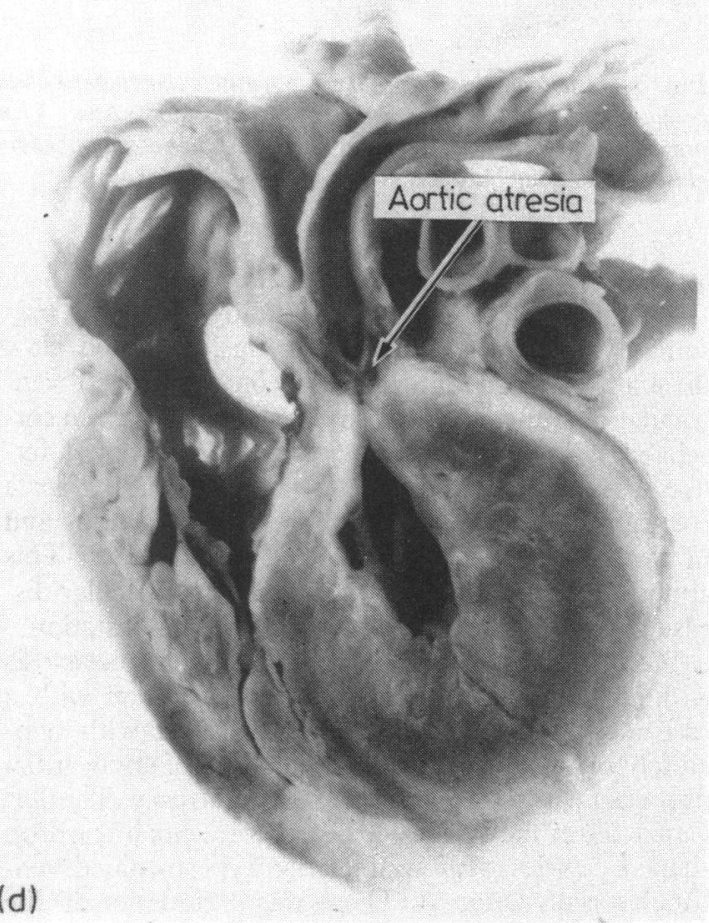

Fig. 3 Long axis four chamber sections through a heant with aoric stenosis ((a) and (b)) compared with a heart with aortic atresia ((c) and (d)). Note moderate endocardial fibroelastotic living of the left ventricle in the heart with a stenotic aortic valve (AoV). RV, right ventricle; $L V$, left ventricle; $R A$, right atrium; $L A$, left atrium. 
ally of intrauterine onset. The course of the disease process was therefore less than 10 months and probably less than four months since organogenesis was complete and the aortic root sizes were equal to or less than those of a 28 week fetus. By focusing on cases of primary endocardial fibroelastosis which had developed over a relatively short and well defined period of time, the aetiology and pathogenesis of this disease process may be clarified. Certain other scientific tools, such as electron microscopy and immunohistochemistry, may be of use in this regard.

At the time of the study CAN was a visiting professor from the Department of Paediatrics, Johns Hopkins University, Maryland, USA. RHA and SYH are supported by the Joseph Levy' Foundation and the British Heart Foundation. LMG is supported by the National Heart Research Fund.

\section{References}

1 Schryer MJP, Karnauchow PN. Endocardial fibroelastosis -etiologic and pathogenetic considerations in children. Am Heart f 1974; 88: 557-65.

2 Mitchell SC, Froelich LA, Banas JS Jr, Gilkeson MR. An epidemiologic assessment of primary endocardial fibroelastosis. Am f Cardiol 1966; 18: 859-66.

3 Factor SM. Endocardial fibroelastosis: myocardial and vascular alterations associated with viral-like nuclear particles. Am Heart f 1978; 96: 791-801.

4 Hutchins GM, Vie SA. The progression of interstitial myocarditis to idiopathic endocardial fibroelastosis. Am $\mathcal{F}$ Pathol 1972; 66: 483-96.

5 Dincsoy MY, Dincsoy HP, Kessler AD, Jackson MA, Sidbury JB Jr. Generalized glycogenosis and associated endocardial fibroelastosis: report of three cases with biochemical studies. F Pediatr 1965; 67: 728-40.

6 Tripp ME, Katcher ML, Peters HA, et al. Systemic carnitine deficiency presenting as familial endocardial fibroelastosis. A treatable cardiomyopathy. $N$ Engl f Med 1981; 305: 385-90.

7 Johnson FR. Anoxia as a cause of endocardial fibroelastosis in infancy. Arch Pathol 1952; 54: 237-47.

8 Kline I, Miller AJ, Pick R, Katz LN. The relationship between human endocardial fibroelastosis and obstruction of the cardiac lymphatics. Circulation 1964; 30: 728-35.

9 Hutchins GM, Moore GW, Jones JF, Miller ST. Postnatal endocardial fibroelastosis of the valve of the foramen ovale. Am f Cardiol 1981;47: 90-4.
10 Chen S, Thompson MW, Rose V. Endocardial fibroelastosis. Family studies with special reference to counseling. F Pediatr 1971; 79: 385-92.

11 Paasch LH, Zook BC. The pathogenesis of endocardial fibroelastosis in Burmese cats. Lab Invest 1980; 42: 197204.

12 Edwards JE. Primary endocardial sclerosis. In: Gould SE, ed. Pathology of the heart. 2nd ed. Springfield, Illinois: Charles C Thomas, 1960: 419-20.

13 Keith JD, Rose V, Manning JA. In: Keith JD, Rowe $\mathrm{RD}$, Vlad $\mathrm{P}$, eds. Heart disease in infancy and childhood. 3rd ed. New York, Toronto, London: Macmillan, 1978:941-57.

14 Becker AE, Anderson RH. The endocardium. In: Pathology of congenital heart disease. London: Butterworths, 1981:391-3.

15 Fixler DE, Cole RB, Paul MH, Lev M, Girod DA. Familial occurrence of the contracted form of endocardial fibroelastosis. Am $\mathcal{F}$ Cardiol 1970; 26: 208-13.

16 Moller JH, Lucas RV Jr, Adams P Jr, Anderson RC, Jorgens J, Edwards JE. Endocardial fibroelastosis. A clinical and anatomic study of 47 patients with emphasis on its relationship to mitral insufficiency. Circulation 1964; 30: 759-82.

17 O'Connor WN, Cash JB, Cottrill CM, Johnson GL, Noonan JA. Ventriculocoronary connections in hypoplastic left hearts: an autopsy microscopic study. Circulation 1982; 66: 1078-86.

18 Buhlmeyer K, Simon B, Mocellin R, Saver U. Clinical angiocardiographic and functional studies in the assessment of critical valvular aortic stenosis. In: Godman MJ, Marquis RM, eds. Paediatric cardiology vol 2. Heart disease in the newborm. Edinburgh, New York: Churchill Livingstone, 1979:220-36.

19 Trusler GA, Freedom RM, Williams WG. Experience in aortic valvotomy in neonates. In: Godman MJ, Marquis RM, eds. Paediatric cardiology vol 2. Heart disease in the newborm. Edinburgh, New York: Churchill Livingstone, 1979:237-42.

20 Neustein HB, Lurie PR, Fugita M. Endocardial fibroelastosis found on transvascular endomyocardial biopsy in children. Arch Pathol Lab Med 1979; 103: $214-9$.

21 Harh JY, Paul MH, Gallen WJ, Friedberg DZ, Kaplan S. Experimental production of hypoplastic left heart syndrome in the chick embryo. Am $\mathcal{F}$ Cardiol 1973; 31: $51-6$.

22 Allan LD, Joseph MC, Boyd EGCA, Campbell S, Tynan M. M-mode echocardiography in the developing human fetus. Br Heart $\mathcal{F}$ 1982; 47: 573-83.

23 Neill CA, Ursell PC. Endocardial fibroelastosis and left heart hypoplasia revisited. Int $\mathcal{f}$ Cardiol (in press). 